\title{
A temática automedicação na abordagem do conteúdo de funções orgânicas: um relato de experiência do estágio de docência em Química
}

\author{
The self-medication theme in addressing the content of organic \\ functions: an experience report of the teaching stage in Chemistry
}

\author{
Danielle Prazeres Reppold (dani.reppold@gmail.com) \\ Universidade Federal do Rio Grande do Sul (UFRGS)
}

Daniele Trajano Raupp (daniele.raupp@ufrgs.br)

Universidade Federal do Rio Grande do Sul (UFRGS)

\author{
Maurícius Selvero Pazinato (mauricius.pazinato@ufrgs.br) \\ Universidade Federal do Rio Grande do Sul (UFRGS)
}

Resumo: O presente trabalho objetiva apresentar um relato de experiência do Estágio de Docência, do curso de Licenciatura em Química da UFRGS, realizado em duas turmas de Química Orgânica do Ensino Médio em uma escola técnica da cidade de Porto Alegre. Alguns dos obstáculos enfrentados na aprendizagem da química orgânica podem ser superados ao se estabelecer uma relação estreita entre os conceitos científicos e o cotidiano do aluno, uma vez que a contextualização pode ser uma importante estratégia no processo de ensino e aprendizagem. Assim, para abordagem do conteúdo funções orgânicas nitrogenadas, foi elaborada uma sequência didática com recursos didáticos variados, utilizando a temática automedicação. A implementação da estratégia de ensino com foco em uma temática relevante para os alunos, contribuiu para a reflexão sobre o potencial da utilização da contextualização de questões socioambientais na busca da superação de uma mera exemplificação de fenômenos científicos no seu cotidiano. A sequência didática a partir de uma contextualização socioambiental se mostrou uma ferramenta de formação crítica dos estudantes, contribuindo para que reconheçam a relevância da ciência em sua vida diária e na sociedade. Além disso, enriqueceu o desenvolvimento do Estágio em Química, o qual constituiu um momento ímpar de vivências e oportunizou aprendizados a todos envolvidos.

Palavras-chave: formação inicial; contextualização; ensino de Química Orgânica.

Abstract: This work aims to present an experience report of a Teaching Internship, of the UFRGS Chemistry Degree course, held in two high school organic chemistry classes at a technical school in the city of Porto Alegre. Some of the obstacles faced in learning organic chemistry can be overcome by establishing a close relationship between scientific concepts and the student's daily life since contextualization can be an important strategy in the teaching and learning process. Thus, to approach the content of nitrogen organic functions, a didactic sequence was developed with varied didactic resources, using the theme of self-medication. The implementation of the teaching strategy with a focus on a relevant topic for students contributed to the reflection on the

Recebido em: 30 /04/ 2020

97

Aceito em: 19/11/2020 
potential of using contextualization of socio-environmental issues in the search for overcoming a mere exemplification of scientific phenomena in their daily lives. The didactic sequence, based on a socio-environmental context, proved to be a tool for critical training of students, helping them to recognize the relevance of science in their daily life and society. Besides, it enriched the development of the Chemistry Internship, which constituted a unique moment of experiences and provided learning opportunities for all involved.

Keywords: Initial formation; contextualization; teaching Organic Chemistry.

\section{INTRODUÇÃO}

O presente trabalho objetiva apresentar um relato de experiência do Estágio de Docência em Ensino de Química I - C, do curso de Licenciatura em Química da Universidade Federal do Rio Grande do Sul. O estágio consiste em uma primeira etapa de observação e uma segunda etapa de regência. Para a regência foi elaborada uma sequência didática sobre Automedicação. O estágio foi realizado na Escola Técnica da cidade de Porto Alegre, RS, com duas turmas de terceira série do Ensino Médio abrangendo aproximadamente 40 alunos - supervisionado pelo professor regente de Química da escola e dois professores adjuntos da universidade.

Para abordagem do conteúdo funções orgânicas foi elaborada uma sequência didática, utilizando a temática automedicação. A utilização de uma abordagem temática possibilita a problematização em situações educacionais, contrapondo-se à abordagem de transmissão do conhecimento, podendo ser relacionadas com o ensino na abordagem Ciência, Tecnologia e Sociedade (CTS). Na perspectiva desse tipo de abordagem, o ensino de Química pode estabelecer conexões entre a sociedade e a ciência, de modo que os conceitos científicos abordados tenham relevância para a compreensão de situações cotidianas, auxiliando o aluno na identificação de problemas e de soluções para os mesmos (KRASILCHIK, 2000). Sendo assim, um ensino de Química, com uma abordagem temática contextualizada, pode contribuir para a compreensão de fenômenos químicos que são relacionados com cotidiano (GABEL, 1993; AULER; DALMOLIN; DOS SANTOS FENALTI, 2009; BRAIBANTE; PAZINATO, 2014), uma vez que a contextualização é considerada um fator chave para aprendizagem (RAUPP; PROCHNOW; DEL PINO, 2020). A contextualização no ensino de ciências tem sido legitimada por documentos oficiais, por professores e pesquisadores da área como

Recebido em: 30 /04/ 2020 
norteadora para uma educação orientada para a cidadania, que permita a aprendizagem significativa de conhecimentos científicos (SILVA; MARCONDES, 2010).

A temática automedicação foi escolhida, em função de que na contemporaneidade, temos acesso facilitado aos fármacos, objetivando ilimitados resultados: desde o rejuvenescimento até eliminação da dor. No contexto desta temática, “o problema da automedicação, um fenômeno bastante discutido na cultura médicofarmacêutica e especialmente preocupante no Brasil por ser uma prática comum da população" (SILVA; PINHEIRO, 2013, p. 92), torna-se relevante de ser abordado no Ensino de Química. O risco do uso indiscriminado de antibióticos, por exemplo, é problema de saúde pública já que pode resultar na resistência bacteriana a essa classe de medicamentos como também em intoxicações (CALIXTO; CAVALHEIRO, 2012).

No território brasileiro, há pouca vigilância em relação à compra e consumo de fármacos que apresentam toxicidade preocupante após ingestão desorientada da droga. A sociedade tem o hábito de armazenar os medicamentos que foram prescritos em momento de crise, para consumir posteriormente em caso de ressurgimento do incômodo e/ou da doença. Assim, a proposta da sequência didática é proporcionar um espaço de reflexão e crítica a respeito da utilização de medicamentos sem acompanhamento médico e os efeitos dessa atitude, construindo uma conexão do fator social com os conhecimentos químico previstos para serem abordados na terceira série do Ensino Médio. Neste trabalho serão apresentadas as etapas de observação e regência, bem como uma análise reflexiva do período de Estágio.

\section{AS ETAPAS DE OBSERVAÇÃO E REGÊNCIA}

\subsection{A Observação}

No primeiro momento do estágio, os licenciandos são orientados a cumprir 30 horas de observação nas turmas que posteriormente aplicarão suas intervenções. Esse é momento adequado para compreender o contexto em que a comunidade escolar está inserida, o perfil da turma e dos alunos que a constituem, as demandas discentes sobre as competências escolares e os recursos didáticos disponíveis para o ensino. Para o enriquecimento das informações, também é solicitado aos graduandos que façam entrevistas semiestruturadas com o professor regente e o diretor da escola, a fim de 
Edição Especial: XVI Encontro sobre Investigação na Escola - EIE

depreender sobre as intervenções da instituição e a rotina escolar instaurada ao longo do tempo que não são perceptíveis no período da observação.

Nas primeiras observações, realizada em uma das turmas em que o Estágio foi desenvolvido (turma 303), as aulas ocorriam nos últimos dois períodos da manhã. Em média, 18 alunos estavam presentes, em seus variados gêneros, os quais eram tranquilos e participativos. Todos estavam na seriação aconselhada, com 17 anos e alguns trabalhavam no Projeto Pescar ou como estagiários no turno inverso. As aulas do professor baseavam-se na exposição do conteúdo com a utilização de slides nas suas aulas, sendo dialogadas. Os alunos recebiam o material da aula por e-mail com um dia de antecedência. Por serem alunos concluintes do Ensino Básico, constantemente os conteúdos de Química eram abordados em uma perspectiva preparatória para vestibulares e prova do Exame Nacional do Ensino Médio (ENEM).

Nas observações realizadas na outra turma (301), as aulas ocorreram nos primeiros dois períodos da manhã. Por este motivo, começavam um pouco mais tarde para que os alunos atrasados pudessem participar. Em média, 22 alunos eram frequentes nessa turma, em seus variados gêneros. Esses alunos eram mais agitados e ocorriam várias conversas paralelas. Assim como na turma 303, todos estavam na seriação aconselhada, com 17 anos e também alguns deles trabalhavam no Projeto Pescar ou como estagiários no turno inverso. Como esta turma tem períodos mais longos que os da turma anterior, no fim da aula o professor solicitava que fossem resolvidas duas questões de vestibular sobre o conteúdo explanado.

Referente às entrevistas, além do seu cargo administrativo e de coordenador, o diretor também é um dos professores regentes da escola. Desta forma, compreende as demandas discentes e docentes, pois atua ativamente no espaço escolar. Uma das maiores dificuldades enfrentadas pela escola, conforme relatado pelo diretor, está no fato de os alunos ingressarem naquele espaço apenas no Ensino Médio. Portanto, eles possuem níveis de conhecimento básicos diferentes e torna-se responsabilidade do professor conseguir lidar com essa diversidade, por vezes, adaptando o cronograma previsto para determinada turma. Sobre a participação ativa dos professores no Projeto Político Pedagógico da escola, reúnem-se todo mês para debaterem mudanças no projeto e na escola, mas a maioria das propostas de modificações não é aceita quando depende da aprovação da Secretaria de Educação. O quadro docente da instituição 
estadual é composto, majoritariamente, por professores contratados. Há vários anos o Governo do Estado do Rio Grande do Sul não realiza concurso público para inserção de professores, nas suas respectivas áreas, nas escolas estaduais. Assim como o Governo do Estado alega não ter condições financeiras para novos concursos, também não há finanças para propor experiências de aprendizagem em espaços não formais para os discentes e nem para aquisições escolares. Desta forma, a escola realiza durante o ano brechós para arrecadação de fundos para compra de novos livros para a biblioteca.

A entrevista com o professor regente foi realizada entre o período das aulas, de forma informal a fim de obter as respostas mais completas, abertas e sinceras possíveis. No turno da manhã, especificamente, ele leciona nas quatro turmas da terceira série. É característico da escola, as aulas dessa série serem regidas no turno da manhã; e a primeira e segunda séries à tarde. Portanto, o professor também leciona no período da tarde. O professor é bastante empenhado nas questões profissionais da licenciatura. É militante ativo do Centro dos Professores do Estado do Rio Grande do Sul (CPERS) e está sempre presente nas mobilizações em prol da melhoria da categoria. Ele tem opiniões convictas em relação ao papel do professor, o qual em sua opinião "deve ir além da mera transmissão do conhecimento químico. O professor necessita provocar reflexões nos discentes de cunho científico e social, pois ambos estão correlacionados".

Na escola estadual, até o momento não havia desenvolvido projetos com outras áreas do conhecimento. As avaliações que o professor considera são diversificadas, dependendo do trimestre. No semestre em que o Estágio foi desenvolvido, os alunos foram avaliados por meio de dois trabalhos produzidos em grupos, resumo do conteúdo utilizado para consulta durante a prova, uma prova, participação e frequência nas aulas, resolução de atividades durante a aula e as anotações nos cadernos.

\subsection{A Regência de Classe}

Após o período de observação, o licenciando cumpre 15 horas de regência em sala de aula, com o propósito de estimular as habilidades docentes e propiciar um espaço de trocas de experiências. É nessa ocasião que o licenciando constrói sua identidade docente, apropriando-se desse espaço que pertence a sua profissão.

A partir desses desafios, foi elaborada uma sequência didática que aborda os conhecimentos de Química Orgânica, conforme previsto pelo cronograma do professor 
regente. Como a regência das turmas ocorreu no segundo semestre do ano de 2019, foi solicitado que desenvolvesse o conteúdo de Funções Orgânicas, em específico: nomenclatura, representações, propriedades físico-químicas e ocorrências cotidianas dos compostos abordados.

Antes de estabelecer o tema que seria versado, foi aplicado um questionário aos discentes, indagando sobre seus conhecimentos prévios, dificuldades com a química, expectativas em relação às posteriores aulas e quais temas que os atraíam. Após o levantamento, o tema Automedicação emergiu como um dos assuntos de maior interesse das turmas. O Quadro 1 apresenta uma síntese das atividades executadas durante o período de regência docente, bem como dos tópicos abordados.

Quadro 1 - Cronograma de Aulas.

\begin{tabular}{|cl|}
\hline AULA & \multicolumn{1}{c|}{$\begin{array}{c}\text { CRONOGRAMA } \\
\text { CONTEÚDO }\end{array}$} \\
\hline $\mathbf{1}$ & Revisão das Funções Oxigenadas \\
\hline $\mathbf{2}$ & Reação de Esterificação \\
\hline $\mathbf{3}$ & "Que medicamentos você ingere quando sente dor?" \\
\hline $\mathbf{4}$ & Automedicação \\
\hline $\mathbf{5}$ & Modelos de Moléculas \\
\hline $\mathbf{6}$ & Análise Estrutural / Funções Nitrogenadas \\
\hline $\mathbf{7}$ & Atividades de Funções Nitrogenadas \\
\hline $\mathbf{8}$ & Atividades de Funções Nitrogenadas \\
\hline
\end{tabular}

$\mathrm{Na}$ primeira aula, foi realizada uma revisão sobre as funções orgânicas oxigenadas, tópico que já tinha sido trabalhado ao longo do trimestre. Para encerrar essa parte do conteúdo, a segunda aula foi sobre reação de esterificação, para que os estudantes compreendessem em quais situações do cotidiano poderiam se deparar com algumas substâncias que possuíam as funções orgânicas que estavam sendo estudadas. Nas Figuras 1 e 2 são apresentadas uma das atividades aplicadas para encerrar o tópico Funções Oxigenadas. 
Edição Especial: XVI Encontro sobre Investigação na Escola - EIE

ISSN: 2595-4520 Vol. 4, n. 2. 2021

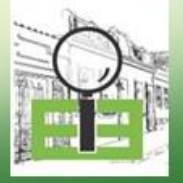

\section{ATIVIDADE!}

- Cada aluno deve apresentar o nome sistemático (oficial) do seu éster e a respectiva reação de esterificação para sua obtenção. Também apresente o nome oficial dos reagentes desta reação. Após, descubra qual aroma esta molécula representa.

1

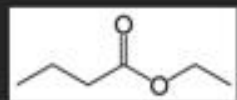

4

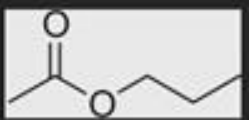

7

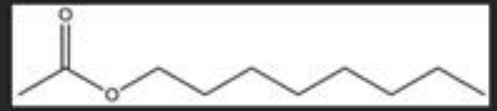

2

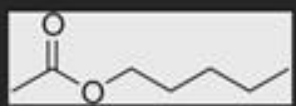

5

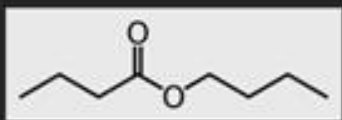

3

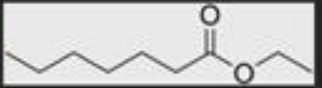

6

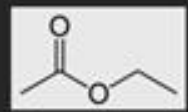

8

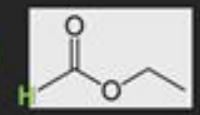

Figura 1 - Atividade sobre Reação de Esterificação.

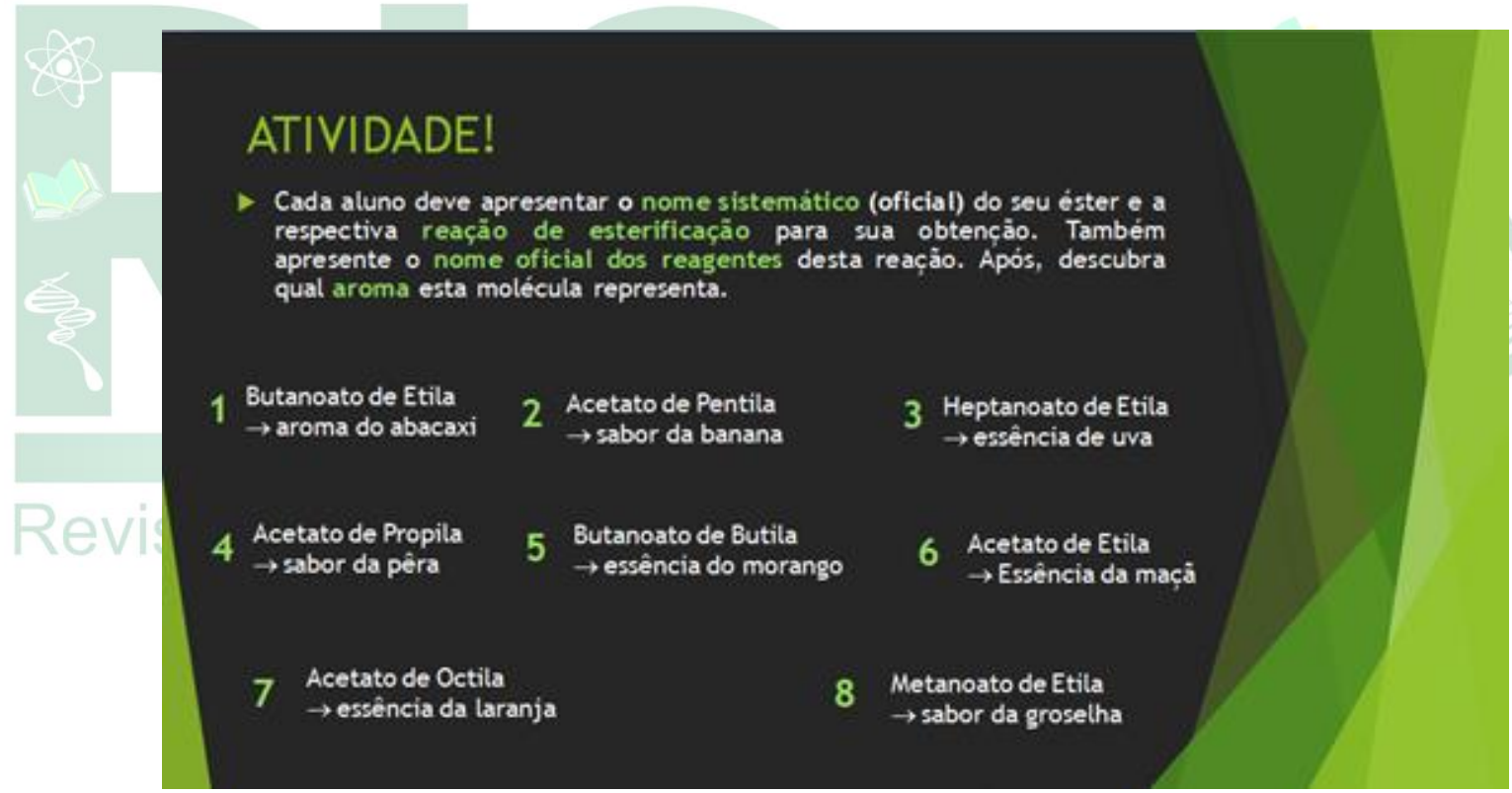

Figura 2 - Presença cotidiana dos respectivos ésteres.

A partir da aula 3 iniciou-se a abordagem da temática de Automedicação. A aula iniciou com a seguinte pergunta norteadora: "Quais medicamentos você ingere quando sente dor?”. Após uma longa exposição dos alunos sobre suas experiências pessoais, quais medicamentos consumiram e em quais contextos foram necessários, alguns medicamentos foram citados, sendo que o princípio ativo de quatro deles foram escolhidos pela estagiária para desenvolver as funções orgânicas nitrogenadas: Dorflex ${ }^{\circledR}$, Tylenol ${ }^{\circledR}$, Amoxil ${ }^{\circledR}$ e Neosaldina ${ }^{\circledR}$. Na Figura 3, são apresentadas as 
estruturas dos princípios ativos desses medicamentos, as quais os alunos se basearam para moldarem, posteriormente, as moléculas utilizando kits.<smiles>CC(=O)Nc1ccc(O)cc1</smiles>

Tylenol (paracetamol)<smiles>Cc1c(N(C)CS(=O)(=O)[O-])c(=O)n(-c2ccccc2)n1C</smiles>

Dorflex (dipinrona)<smiles>Cn1c(=O)c2c(ncn2C)n(C)c1=O</smiles>

Neosaldina (cafeína)<smiles>CC1(C)S[C@@H]2[C@H](NC(=O)[C@@H](N)c3ccc(O)cc3)C(=O)N2[C@H]1C(=O)O</smiles>

Amoxil (amoxicilina)

Figura 3 - Princípios ativos dos medicamentos estudados em sala de aula.

$\mathrm{Na}$ quarta aula, de maneira expositiva, foram abordados os riscos do consumo prolongado e das consequências das superdosagens desses medicamentos, por exemplo, os benefícios, as consequências da automedicação e a necessidade de buscar os órgãos de saúde quando apresentam algum quadro anormal. Posteriormente, na quinta aula foi solicitado que a turma se dividisse em quatro grupos e manuseassem os kits de modelos moleculares, que a universidade emprestou para aplicar na sala de aula. Cada grupo montou a estrutura química do princípio ativo de um dos medicamentos escolhidos na aula expositiva.

Após essa atividade de modelagem, um representante de cada grupo apresentou o modelo de molécula construído. A turma debateu as semelhanças e diferenças nas estruturas construídas, identificando algumas funções orgânicas oxigenadas e, então, a partir daquele momento, as funções orgânicas nitrogenadas. Primeiramente, eles observaram que havia nitrogênio em todas as estruturas. Após, analisaram os átomos vizinhos e a estrutura funcional semelhante. Então, foi introduzido o conceito de funções orgânicas nitrogenadas, em que foram desenvolvidas as propriedades físicas das substâncias, grupos funcionais, aplicações no cotidiano e nomenclatura, ocupando também o sexto período. 
Edição Especial: XVI Encontro sobre Investigação na Escola - EIE

Como se tratava de duas turmas da terceira série do Ensino Médio, no último trimestre do ano, eles solicitaram exercícios que os preparassem para o ENEM e vestibulares fossem abordados. Desta forma, os sétimo e oitavo períodos foram designados para desenvolvimentos de exercícios, tanto aqueles que visassem para as aplicações cotidianas quanto aqueles que haviam sido aplicados em provas de ingresso nos anos anteriores.

\section{ANÁLISE E DISCUSSÃO DO RELATO}

Focando no período de regência docente, a partir do tema medicamentos abordouse a automedicação, sendo desenvolvida uma sequência didática contextualizada. Conforme Santos (2008), a vaga inserção de questões do cotidiano nos debates em sala de aula pode não significar a discussão de tópicos relevantes para a formação do cidadão crítico ou não estimular o aluno na busca por conhecimentos científicos. Há necessidade de o docente compreender as diferentes abordagens de questões socioambientais para entender que formar alunos críticos ultrapassa a mera identificação dos fenômenos científicos nos seus cotidianos. A contextualização estimula atitudes e valores humanísticos e compreende (e não somente identifica) as manifestações científicas no cotidiano. Semelhante as categorizações de Santos e Mortimer (1999), Santos (2008) e Vázques González (2004), foram propostas três categorias que definem os tipos de abordagens contextualizadas no Ensino de Química, sendo descritas como:

- Abordagem Cotidiana: o uso de contextualização como sinônimo para abordagem de situações do cotidiano apenas exemplificando de forma pontual uma ocorrência de um fenômeno químico do cotidiano, sem propiciar uma reflexão social, econômica e/ou cultural mais ampla.

- Abordagem Metodológica: quando as situações do cotidiano são utilizadas como estratégia para tentar facilitar a compreensão e aprendizagem dos conceitos químicos, todavia não tem como finalidade a formação crítica.

- Abordagem Socioambiental: desenvolvimento do cidadão crítico, de modo a facilitar a compreensão do aluno sobre a utilidade da ciência no nosso cotidiano, melhorado sua capacidade de atuação na sociedade.

Desta forma, objetivou-se a abordagem socioambiental com a elaboração e aplicação da sequência didática sobre automedicação. Buscou-se a construção dos

Recebido em: 30 /04/ 2020

105

Aceito em: $19 / 11 / 2020$ 
conhecimentos conceituais, procedimentais e atitudinais, conduzindo a reflexão sociocrítica sobre a superdosagem de medicamentos e as consequências pessoais e sociais sobre essa iniciativa. Esse foco na construção de um repertório de conhecimentos sobre a aplicação de um dado conceito, é o que o torna significativo e relevante para os alunos. (RAUPP; PROCHNOW; DEL PINO, 2020).

Os alunos foram bastante participativos, desde o princípio da regência docente. Na primeira aula, foram utilizados slides para tratar sobre a Reação de Esterificação, pois era um recurso largamente utilizado pelo professor regente. Porém, para explicar um detalhe que não estava nos slides, a estagiária recorreu ao quadro branco e percebeu maior atenção e dedicação por parte deles. Foi possível compreender que há três anos eles tinham aulas com o mesmo professor que empregava o mesmo recurso didático, então o quadro branco era um recurso novo para eles. Fato que fez com que a estagiária se sentisse confortável naquele momento, construindo aquele conhecimento concomitante com as resoluções das dúvidas, confirmações de compreensão e conhecimentos prévios dos alunos.

Há várias formas de contextualização segundo a literatura, conforme abordado anteriormente. Almejou-se durante o desenvolvimento do Estágio a abordagem socioambiental, visto que a intenção não foi apenas utilizar um assunto cotidiano para exemplificar um fenômeno químico, ou como um simples motivador. A intenção foi incentivar o debate crítico desse conhecimento para a vida em sociedade dentro da sala de aula. Desta forma, a partir da temática Medicamentos, já sugerida por pesquisas da área (DOS SANTOS; DA COSTA SOARES, 2018; PAZINATO et al., 2012), optou-se por abordar uma atitude recorrente nessa faixa etária: a automedicação. Quando a pergunta norteadora foi escrita no quadro, os estudantes se manifestaram com intensidade, queriam contar sobre os medicamentos que consumiam e quais foram as circunstâncias que o levaram a este ato. Enquanto um contava sua experiência pessoal, outro se identificava e lembrava de uma história para socializar. Viram, naquele espaço, a oportunidade de falarem sobre suas vidas, experiências e angústias para os demais, e igualmente um espaço que aproximou o conhecimento científico para compreender a melhor forma de lidar com esse ato tão comum e instaurado pela sociedade. Afinal, para eles, medicamentos como Tylenol ${ }^{\circledR}$ e Neosaldina ${ }^{\circledR}$, podem ser comprados em larga 
escala, sem receitas médicas, associados à ideia de que não há riscos em consumir seja qual for a dose.

Durante a aula expositiva dialogada sobre a automedicação, os estudantes apresentaram alguns receios sobre o consumo desenfreado de alguns medicamentos. Portanto, foi realizada uma pausa e esclarecimento para eles: a Química não deve ser temida, mas compreendida. $\mathrm{O}$ objetivo da sequência didática não foi preocupar a respeito do consumo de algum medicamento em consequência dos efeitos colaterais, mas que o consumo ocorra de forma consciente e que se informem sobre a dose aconselhada. Igualmente, compreender o que é a overdose, qual a diferenciação entre fármaco e droga, bem como entre remédio, medicamento genérico e de referência.

Outro recurso didático que se destacou foi a atividade de modelagem. Após três anos estudando Química e interpretando as moléculas como representações bidimensionais, naquele momento se apropriaram da ideia que as estruturas químicas são tridimensionais. Os estudantes tentaram, diversas vezes, planificar a molécula, porém para algumas das moléculas abordadas tal conformação não era adequada, sendo desenvolvidas habilidades de visualização espacial do arranjo resultante das interações entre os átomos de carbono, hidrogênio e dos grupos funcionais explorados (principalmente os presentes em funções nitrogenadas).

\section{Vista CONSIDERAÇÕES FINAIS}

Durante o período de Estágio, o graduando em Licenciatura em Química constrói sua identidade docente de forma orientada pelos professores orientadores e professor regente da turma. Apropria-se de um espaço que será seu em um futuro próximo e por meio desse processo de ensino e aprendizagem orientado, a experiência torna-se enriquecedora para sua formação enquanto futuro docente. Simultaneamente, oportuniza-se ao estudante do Ensino Básico acesso a recursos que a escola não detém, a novas metodologias de ensino que estão sendo aplicadas, analisadas e estudadas no Ensino Superior. Também, há benefícios para o professor regente, que enquanto espectador e incentivador da identidade que se forma no graduando, conhece novas metodologias que poderão ser empregadas por ele em outras turmas. Por fim, destaca-se que o Estágio Docente é uma atividade importante e necessária para todas as esferas do ensino, tornando-se uma experiência única, enriquecedora e transformadora. 


\section{REFERENCIAS}

AULER, Décio; DALMOLIN, Antonio Marcos Teixeira; DOS SANTOS FENALTI, Veridiana. Abordagem temática: natureza dos temas em Freire e no enfoque CTS. Alexandria: revista de educação em ciência e tecnologia, v. 2, n. 1, p. 67-84, 2009.

BRAIBANTE, Mara Elisa Fortes; PAZINATO, Maurícius Selvero. O Ensino de Química através de temáticas: contribuições do LAEQUI para a área. Ciência e Natura, v. 36, n. II, p. 819-826, 2014.

CALIXTO, Carolina Maria Fioramonti; CAVALHEIRO, É. T. G. Penicilina: efeito do acaso e momento histórico no desenvolvimento científico. Química Nova na escola, v. 34, n. 3, p. 118-123, 2012.

DA SILVA, Maria Laura Maciel; PINHEIRO, Paulo César. A educação Química e o problema da Automedicação: Relato de Sala de Aula. Química Nova na Escola, v. 35, n. 2, p.92-99, 2013.

DOS SANTOS, Grazielle Alves; DA COSTA SOARES, Joceline Maria. O Ensino de Química por meio de um projeto educativo intitulado: a identificação de compostos orgânicos nos medicamentos. Multi-Science Journal, v. 1, n. 13, p. 15-19, 2018.

GABEL, D. Use of the particle nature of matter in developing conceptual understanding. Journal of Chemical Education, v.70, n.3, 1993.

KRASILCHIK, Myriam. Reformas e realidade: o caso do ensino das ciências. São Paulo em perspectiva, v. 14, n. 1, p. 85-93, 2000.

PAZINATO, Maurícius S.; BRAIBANTE, Hugo Tubal., BRAIBANTE; Mara Elisa Fortes; TREVISAN, Marcele Cantarelli; SILVA, Giovanna Stefanello. Uma abordagem diferenciada para o ensino de funções orgânicas através da temática medicamentos. Química Nova na Escola, v. 34, n. 1, p. 21-25, 2012.

RAUPP, Daniele Trajano; PROCHNOW, Tania Renata; DEL PINO, José Cláudio. História e contextualização no ensino de estereoquímica: uma proposta de abordagem para o ensino médio. Revista Contexto \& Educação, v. 35, n. 112, p. 432-455, 2020.

SANTOS, Wildson Luiz Pereira dos; MORTIMER, Eduardo Fleury. Concepções de professores sobre contextualização social do ensino de química e ciências. Reunião Anual da Sociedade Brasileira de Química, v. 22, 1999.

Recebido em: $30 / 04 / 2020$ 
Edição Especial: XVI Encontro sobre Investigação na Escola - EIE

SANTOS, Wildson Luiz Pereira. Contextualização no ensino de ciências por meio de temas CTS em uma perspectiva crítica. Ciência \& Ensino (ISSN 1980-8631), v. 1, 2008.

SILVA, Erivanildo Lopes da; MARCONDES, Maria Eunice Ribeiro. Visões de contextualização de professores de química na elaboração de seus próprios materiais didáticos. Ensaio Pesquisa em Educação em Ciências (Belo Horizonte), v. 12, n. 1, p. 101-118, 2010.

VÁZQUEZ GONZÁLEZ, C. Reflexiones y ejemplos de situaciones didácticas para una adecuada contextualización de los contenidos científicos en el Proceso de enseñanza. Revista Eureka sobre Enseñanza y Divulgación de lãs Ciencias, v.1, n.3, p. 214-223, 2004.

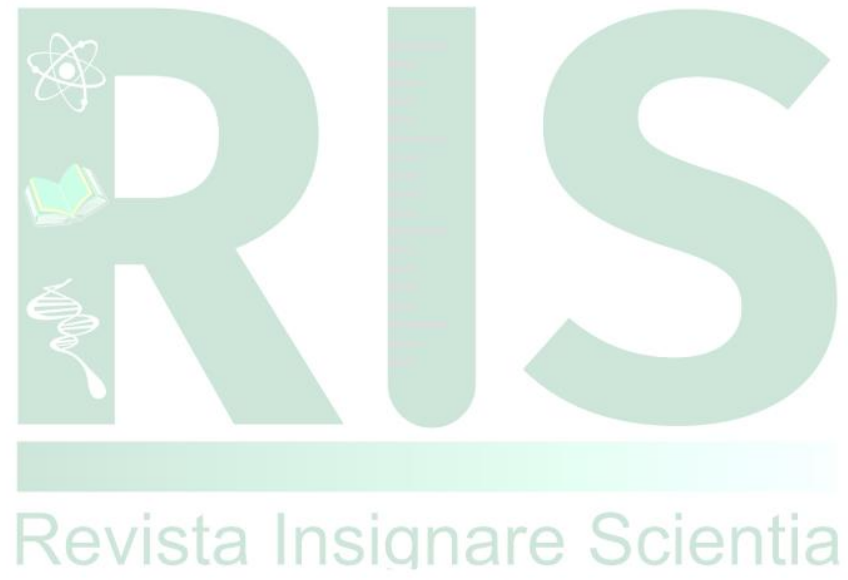

